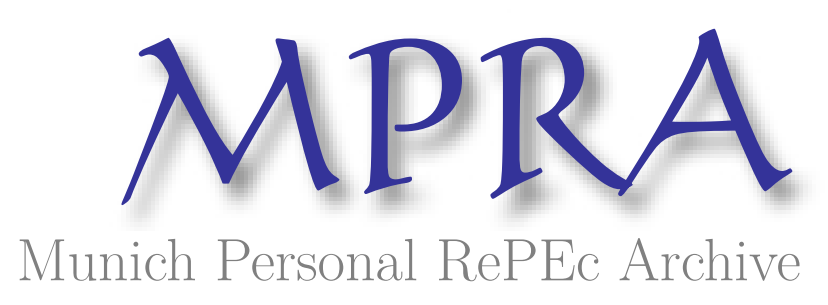

Best-price Guarantees as a Quality Signal

Stephan, Levy

2 November 2004

Online at https://mpra.ub.uni-muenchen.de/13466/

MPRA Paper No. 13466, posted 18 Feb 2009 09:38 UTC 


\title{
Best-price Guarantees as a Quality Signal
}

\author{
by
}

\author{
Stephan M. Levy \\ stephan-levy@verizon.net
}

This paper shows that best-price guarantees can enhance welfare, in contrast to findings in recent literature. While a high-quality monopolist can signal its quality strictly through high prices, using both price and a best-price guarantee may allow the firm to signal its quality with a smaller price distortion. A low-quality monopolist will not mimic its high-quality counterpart by offering a best-price guarantee, because the accompanying restrictions are too costly. Best-price guarantees are similar to money-back guarantees and other more general contracts in their ability to allow less costly signaling. The welfare enhancing capabilities of these contracts imply that the antitrust authorities should regard them more favorably.

I would like to thank Eric Rasmusen, Anjan Thakor, Tom Lyon, Wayne Winston, Charles Thomas, David Sharp and two anonymous referees for their helpful comments and suggestions. All errors are my own. The views expressed in this paper are those of the author. 


\section{Best-price Guarantees as a Quality Signal}

\section{Introduction}

The notion that uninformed consumers can infer a product's quality from its price was recognized long before economists developed the fundamentals of signaling games. However, game theoretic formalization has shed light on how firms can make signaling work. For example, the manufacturer of a high quality good can signal quality through a higher price than would be optimal if consumers were fully informed about product quality. Signaling in this manner is credible because, though high prices reduce profits for both low and high quality firms, a low-quality manufacturer suffers greater losses than its high-quality counterpart. ${ }^{1}$ Thus, a low-quality firm will not find it profitable to mimic a high-quality firm's pricing strategy.

Klein and Leffler (1981), Shapiro (1983), and Bagwell and Riordan (1991) have established the foregoing point through various means. Bagwell and Riordan's model, in particular, shows that price signaling diminishes in strategic value as consumers gain information over time about a non-durable good's quality. They do not consider mechanisms that may credibly allow the firm to disseminate this information more quickly, such as a best-price guarantee.

\footnotetext{
1 "Quality" may take different meanings. Sometimes, quality refers to the likelihood that a product will be defective. Here, quality refers to consumers' tastes and preferences between similar goods. For example, Coca-Cola may be viewed by many consumers as being a higher quality product than Check Cola.
} 
Best-price provisions, or most-favored customer contracts (MFCCs), are sales contracts that specify a rebate for customers when the firm charges certain prices for its product. ${ }^{2}$ While these contracts take on a variety of forms, in this paper I examine retroactive two-party MFCC, which require the firm to pay the customer a penalty should the firm lower its price during some specified period. The penalty is usually the difference between the original price and the "sale" price (but may also have an alternate specification). In effect, the MFCC commits the firm to not lower its own price in the future. These contracts may be valid for any length of time and are generally easily enforced.

MFCCs may be used in a variety of ways. Cooper (1986) models the use of retroactive two-party MFCCs by Bertrand oligopolists, selling products of known quality. Cooper shows that at least one firm will unilaterally adopt an MFCC in equilibrium. ${ }^{3}$ If a firm offers a MFCC, its rival can profitably charge higher prices, even without offering an MFCC itself. The MFCC adopter, in effect, communicates to its rival its willingness to (tacitly) collude, and burns its bridges as proof. Provided the rival does not charge too low a price, the adopter will not lower its own price.

In a similar vein, Butz (1991) shows that a monopolist producer of a durable good of known quality will offer a retroactive two-party MFCC in order to commit credibly to not lowering price in the future. Without such a contract, the monopolist has incentive to increase output in each period, imposing additional costs on its previous customers. The monopolist's inability to commit to limiting the

\footnotetext{
${ }^{2}$ Contemporaneous two-party MFCCs commit the firm to eschew price discrimination amongst its customers within each period. Contemporaneous three-party MFCC commit the firm to match the best price offered by its competitors. A three-party retroactive MFCC commits the firm to pay previous customers a rebate should they find that a competitor had a lower price.

${ }^{3}$ Neilson and Winter (1993) show that both firms will adopt a MFCC only under the undesirable assumption that demand for one firm's product is less responsive to changes in its own price than to changes in its rival's price.
} 
good's stock induces consumers to reduce their willingness to pay for the good. MFCCs allow the monopolist to commit credibly to higher prices and retain all of its monopoly power. ${ }^{4}$

This paper studies the use of a retroactive two-party best-price provision, and a more general form of contractual commitment, as part of a multivariable signal of product quality. Consumers' uncertainty about product quality induces firms producing high-quality products to distinguish themselves by adopting MFCCs. As a result, welfare is greater than if MFCCs had not been adopted. This result contrasts sharply with the results from Cooper (1986) and Butz (1991), in which consumers were fully informed about product quality and the MFCC was welfare reducing.

Following Bagwell (1991), I assume a monopolist is either high-quality (type H) or low-quality (type L). The firm learns its randomly determined type prior to any pricing decisions, but consumers are uninformed about the firm's product quality in period 1 . They become fully informed before making any purchases in period 2 .

The type $\mathrm{H}$ firm distinguishes itself from the type $\mathrm{L}$ firm by offering a first period price that is higher than its full-information monopoly price - the price it would find most profitable to charge when consumers are fully informed. I show that offering a best-price guarantee allows the high-quality producer to signal its type at a lower price, because a low-quality firm is unwilling to offer a best-price guarantee at any price greater than its own full-information price. If the low-quality firm maintains a high

\footnotetext{
${ }^{4}$ Contemporaneous MFCCs appear to be less powerful devices for credibly committing to maintain high prices. Besanko and Lyon (1992) posit a model similar to Cooper's, in which the oligopolist offers a contemporaneous MFCC in order to tacitly collude with its rival. This type of provision is not necessarily adopted by any firm in an equilibrium since price discrimination is profitable if the high value customers are numerous enough. More over, the empirical work of Crocker and Lyon (1994) shows that the three-party MFCCs used in long-term contracts tend to facilitate efficient price adjustment rather than collusion. These types of MFCCs place no restrictions on the firm's ability to lower its own prices, but instead serve to limit its ability to raise prices. Within the context of my model, only the ability of the firm to cut its own price is important.
}

(continued...) 
price, then its sales will suffer in the future once consumers learn the true quality. If it lowers its price in the future, then it will be able to sell its product, but will have to pay the penalty stipulated in the MFCC. Thus, the high-quality firm can use an MFCC to distinguish itself from its low-quality counterpart, and the associated lower prices raise welfare. ${ }^{5}$

The paper is structured as follows. Section II characterizes the solution with only price as a signal. Section III shows that the use of a best-price provision allows the high-quality monopolist to signal at a lower price, thus raising welfare. Section IV examines the signaling game with a more general penalty contract. Section V concludes the paper.

\section{Classic price signaling}

The basic model is from Bagwell (1991), with the exception that the monopolist's quality choice is exogenous. Consider a 2-period model in which consumers purchase a non-durable good from a monopolist. ${ }^{6}$ Nature determines the quality of the good prior to any actions by the players. Let $i \in\{L$, $H\}$ index quality. Demand for the good of quality $i$ in period $t$ is given by $D\left(p_{t}, b_{t}\right)$, where $p_{t}$ is price, $b_{t} \in[0,1]$ is the probability with which consumers believe the good to be type $i=H$ and $t$ indexes time. $D\left(p_{t}, b_{t}\right)$ is decreasing in $p_{t}$ and increasing in $b_{t}$. Let $c_{i}$ be the marginal cost of the good of quality $i$,

${ }^{5}$ MFCCs are an effective signal because they are a credible, legally binding commitment to a particular price level. Riordan (1986) also recognizes the importance of commitment in a quality signaling game. However, the commitment mechanism in Riordan is exogenous. In contrast, the choice of adopting a MFCC as a commitment mechanism is endogenous to my model.

${ }^{6}$ Best-price guarantees are frequently used in non-durable goods settings. For example, retailers offer MFCCs to customers as protection (on durable and non-durable goods) from missing a sale. Also, consider a scenario in which consumers may be indifferent between purchasing today and tomorrow (at today's price), or have discount factors very close to one. Then non-durable goods begin to approach being durable goods, in the limit. By viewing the model in the present setting, we can avoid complications resulting from the Coase Conjecture and from the monopolist's need to hold periodic sales when the number of consumers with low willingness-to-pay becomes large. 
with $c_{L}<c_{H}$. Let $\mathrm{d} \in[0,1]$ be the discount factor. Let $\tilde{p}$ be the highest price for which any consumer would be willing to pay for the monopolist's product $-\operatorname{implying} D(\tilde{p}, 1)=0$. In period 1 , consumers are uninformed as to the quality of the monopolist's product. In period 2, consumers are fully informed about the product's quality.

The type $L$ firm's profit function for this game is given as

$$
\Pi\left(p_{1}, c_{L}, b_{1}, 0,0\right)+\delta \Pi\left(p_{2}, c_{L}, 0,0,0\right) .
$$

Profits in period one are a function of the price in period one, the type $L$ firm's marginal cost, and consumers' beliefs about the product's quality. ${ }^{7}$ Profits in period two, when quality is known, are a function of the price in period two and the type $L$ firm's marginal cost, and are discounted appropriately. Similarly, the type $H$ firm's profit function for this game is given as

$$
\Pi\left(p_{1}, c_{H}, b_{1}, 0,0\right)+\delta \Pi\left(p_{2}, c_{H}, 1,0,0\right) .
$$

Assume that for all $\forall(c, b) \Pi(p, c, b, 0,0)$ is strictly concave in $p$, with a well-defined maximizer $p(c, b, 0,0)$ at which profit is positive: $\Pi(p(c, b, 0,0), c, b, 0,0)>0$. Further assume that $p(c, b, 0,0)$ is increasing in $c \forall(c, b)$, that is $\Pi_{p c}=-D_{p}>0$. Also assume that $\forall(c, b) p(c, b, 0,0)$ is increasing in $b$, that is $\Pi_{b}=(p-c) D_{p b}+D_{b}>0$.

Let

$$
p\left(c_{L}, 0,0,0\right)=\operatorname{argmax} \Pi\left(p, c_{L}, 0,0,0\right),
$$

and

\footnotetext{
${ }^{7}$ The last two arguments of the profit function represent whether or not an MFCC has been offered. These arguments take the value of zero in equations (1) and (2) and are defined in Section III.
} 


$$
p\left(c_{H}, 1,0,0\right)=\operatorname{argmax} \Pi\left(p, c_{H}, 1,0,0\right)
$$

be the full-information (first-best) monopoly prices for the low-quality firm and the high-quality firm respectively. Note that $p\left(c_{L}, 0,0,0\right)<p\left(c_{H}, 1,0,0\right)$ because $D\left(p_{t}, b_{t}\right)$ increases in $b_{t}$.

Because consumers do not know the firm's true type in period 1, a type $H$ firm would like to signal its type through price. Assume

$$
\Pi\left(p\left(c_{L}, 0,0,0\right), c_{L}, 0,0,0\right)<\Pi\left(p\left(c_{H}, 1,0,0\right), c_{L}, 1,0,0\right),
$$

which implies that a type $L$ firm would find it profitable to offer the high-quality, full-information price if doing so induced consumers to believe that its true type were $H$. Consequently, when consumers are uninformed, a type $H$ firm cannot signal its type using its first-best price.

I use backwards induction to find the equilibrium prices charged by each type of firm in this game. In period 2, when all consumers are informed about the product's quality, the firm will set its price at its full-information level. Equilibrium profits in period 2 are $\Pi\left(p\left(c_{L}, 0,0,0\right), c_{L}, 0,0,0\right)$ and $\Pi\left(p\left(c_{H}, 1,0,0\right), c_{H}, 1,0,0\right)$ for the type $L$ firm and the type $H$ firm respectively.

Now consider period 1 , when all consumers are uninformed about the product's quality. In a separating equilibrium, the type $H$ firm selects a price such that a type $L$ firm will charge its fullinformation price and will not find it profitable to mimic. Any price, $P^{*}$ offered by $H$ in a separating equilibrium must satisfy the following incentive compatibility constraint:

$$
\Pi\left(P^{*}, c_{L}, 1,0,0\right) \leq \Pi\left(p\left(c_{L}, 0,0,0\right), c_{L}, 0,0,0\right) .
$$

The price $P^{*}$ that satisfies (the quadratic) equation (6) with equality has two roots,

$$
\underline{P}<p\left(c_{L}, 0,0,0\right)<p\left(c_{H}, 1,0,0\right)<\bar{P}
$$


Figures 1 and 2 show the profit functions for each type of firm and the prices which satisfy the incentive compatibility constraint for linear and constant elasticity demand curves, respectively. This leads to the following theorem, which is nearly identical to the theorem in Bagwell (1991).

Theorem 1: There exists a unique Cho-Kreps Intuitive Criterion equilibrium outcome in which $p_{1}=\bar{P}, p_{2}=p\left(c_{H}, 1,0,0\right)$ for the type H firm and $p_{1}=p_{2}=p\left(c_{L}, 0,0,0\right)$ for the type L firm.

The proof to the Theorem is analogous to the proof of the theorem in Bagwell (1991) and is not formally presented here.

A manufacturer of a high-quality good is able to signal its type effectively with the high price because a low-quality manufacturer cannot as easily accommodate the reduction in output brought on by higher prices. In a separating equilibrium, the type $L$ firm does not distort its price and the type $H$ firm sets a price such that equation (6) is satisfied, $p_{1} \notin(\underline{P}, \bar{P})$. The high-quality firm will seek to minimize the distortion from its full-information equilibrium price and quantity. The type $H$ firm will therefore prefer to set its first-period price at $p_{1}=\bar{P}$ because

$$
\begin{gathered}
\Pi\left(\bar{P}, c_{H}, 1,0,0\right)-\Pi\left(\underline{P}, c_{H}, 1,0,0\right)= \\
\Pi\left(\bar{P}, c_{H}, 1,0,0\right)-\Pi\left(\underline{P}, c_{H}, 1,0,0\right)+\Pi\left(\bar{P}, c_{L}, 1,0,0\right)-\Pi\left(\underline{P}, c_{L}, 1,0,0\right)= \\
\left(c_{H}-c_{L}\right)(D(\underline{P}, 1)-D(\bar{P}, 1))>0 .
\end{gathered}
$$

This result emanates from the single-crossing property:

$$
\frac{\partial \Pi\left(p, c_{H}, 1,0,0\right)}{\partial p}>\frac{\partial \Pi\left(p, c_{L}, 0,0,0\right)}{\partial p}
$$

As seen in Figures 1 and 2, a type $H$ firm is less affected by higher prices than a type $L$ firm. Profits drop much faster as prices rise above $p\left(c_{H}, 1,0,0\right)$ for a type $L$ firm than for a type $H$ firm, as the 
figures indicate. Consumers, realizing this, know that only a high-quality firm could offer the high price, and they update their beliefs accordingly.

\section{Signaling with Best-price Guarantees}

Now consider the two-period game in which the monopolist may adopt a MFCC at the start of the first period. As before, consumers are fully informed about the firm's type only in period 2.

However, the firm's profits in the second period now depend upon the price and consumers' beliefs from period 1 .

Let $m_{t}=1$ indicate that the firm has adopted a MFCC in period $t$. Let $m_{t}=0$ indicate that the firm did not adopt a MFCC in period $t$. Let $\phi$ represent the size of the penalty stipulated in the MFCC. Per period profits for firm $i$ are

$$
\Pi\left(p_{t}, c_{i}, b_{t}, m_{t-1}, \phi\right)=\left(p_{t}-c_{i}\right) D\left(p_{t}, b_{t}\right)-m_{t-1} \phi
$$

Let the MFCC stipulate the following penalty function:

$$
\phi\left(p_{t-1}, p_{t}, b_{t-1}\right)=\left\{\begin{array}{cl}
\left(p_{t-1}-p_{t}\right) D\left(p_{t-1}, b_{t-1}\right) & \text { if } p_{t-1}>p_{t} \\
0 & \text { if } p_{t-1} \leq p_{t}
\end{array} .\right.
$$

Total profits at date $t$ for firm $i$ are:

$$
\sum_{t}^{T} \delta^{(t-1)} \Pi\left(p_{t}, c_{i}, b_{t}, m_{t-1}, \phi\right)
$$

where $\mathrm{d} \in[0,1]$ is the discount factor.

A type $L$ firm's profits are

$$
\left(p_{1}-c_{L}\right) D\left(p_{1}, b_{1}\right)+\delta\left(p_{2}-c_{L}\right) D\left(p_{2}, 0\right)-\delta m_{1} \phi\left(p_{1}, p_{2}, b_{1}\right),
$$

while a type $H$ firm's profits are 


$$
\left(p_{1}-c_{H}\right) D\left(p_{1}, b_{1}\right)+\delta\left(p_{2}-c_{H}\right) D\left(p_{2}, 1\right)-\delta m_{1} \phi\left(p_{1}, p_{2}, b_{1}\right) .
$$

Once again, I use backwards induction to solve for equilibrium prices. In period 2, consumers know the firm's quality. However, unlike the game with the restriction $m_{1}=0$, the profit maximizing period 2 price depends upon whether or not a MFCC was adopted in period 1 and the period 1 price. If $m_{1}=0$, then there was no MFCC and each type of firm will offer its full-information price in period 2: $p_{2}=p\left(c_{L}, 0,0,0\right)$ if quality is low, and $p_{2}=p\left(c_{H}, 1,0,0\right)$ if quality is high. Likewise, if $m_{1}=1$ and $p_{1}$ is less than or equal to the full-information price, then in period 2 each type of firm will offer its full information price because the MFCC penalty is zero. However, if $m_{1}=1$, and $p_{1}>p_{2}$, then the firm will have to pay a penalty in period 2 . Since the penalty is dependent upon the value of $p_{2}$, each type of firm faces a constrained optimization problem in the second period. The type $L$ firm solves

$$
\begin{gathered}
\max _{p_{2}}\left(p_{2}-c_{L}\right) D\left(p_{2}, 0\right)-\left(p_{1}-p_{2}\right) D\left(p_{1}, b_{1}\right) \\
\text { s.t. } p_{1}-p_{2}>0,
\end{gathered}
$$

while the type $H$ firm solves

$$
\begin{gathered}
\max _{p_{2}}\left(p_{2}-c_{H}\right) D\left(p_{2}, 1\right)-\left(p_{1}-p_{2}\right) D\left(p_{1}, b_{1}\right) \\
\text { s.t. } p_{1}-p_{2}>0 .
\end{gathered}
$$

Let

$$
p_{m}\left(c_{L}, 0,1, \phi\right)=\left.\operatorname{argmax} \Pi\left(p_{1}, c_{L}, 0,1, \phi\right)\right|_{p_{1} \geq p_{2}},
$$

be the solution to the constrained optimization problem in equation (15) and let 


$$
p_{m}\left(c_{H}, 1,1, \phi\right)=\left.\operatorname{argmax} \Pi\left(p_{2}, c_{H}, 1,1, \phi\right)\right|_{p_{1} \geq p_{2}},
$$

be the solution to the constrained optimization problem in equation (16).

The optimal second period price for a type $L$ firm is summarized below and in Figure 3:

$$
p_{2}=p\left(c_{L}, 0,1, \phi\right)= \begin{cases}p\left(c_{L}, 0,0,0\right), & p_{1} \in\left[0, p\left(c_{L}, 0,0,0\right)\right], \\ p_{1}, & p_{1} \in\left(p\left(c_{L}, 0,0,0\right), \bar{p}_{L}\left(b_{1}\right)\right], \\ p_{m}\left(c_{L}, 0,1, \phi\right), & p_{1} \in\left(\bar{p}_{L}\left(b_{1}\right), \tilde{p}_{L}\left(b_{1}\right)\right] \\ p\left(c_{L}, 0,0,0\right), & p_{1} \in\left(\tilde{p}_{L}\left(b_{1}\right), \infty\right) .\end{cases}
$$

where $\bar{p}_{L}\left(b_{1}\right)=\left\{p_{2}=p_{1}\right\} \cap\left\{p_{2}=p_{m}\left(c_{L}, 0,1, \phi\right)\right\}$ and

$\tilde{p}_{L}\left(b_{1}\right)=\left\{p_{2}=p_{m}\left(c_{L}, 0,1, \phi\right)\right\} \cap\left\{p_{2}=p\left(c_{L}, 0,0,0\right)\right\}$.

The optimal second period price for a type $H$ firm is:

$$
p_{2}=p\left(c_{H}, 1,1, \phi\right)= \begin{cases}p\left(c_{H}, 1,0,0\right), & p_{1} \in\left[0, p\left(c_{H}, 1,0,0\right)\right], \\ p_{1}, & p_{1} \in\left(p\left(c_{H}, 1,0,0\right), \bar{p}_{H}\left(b_{1}\right)\right], \\ p_{m}\left(c_{H}, 1,1, \phi\right), & p_{1} \in\left(\bar{p}_{H}\left(b_{1}\right), \tilde{p}_{H}\left(b_{1}\right)\right], \\ p\left(c_{H}, 1,0,0\right), & p_{1} \in\left(\tilde{p}_{H}\left(b_{1}\right), \infty\right) .\end{cases}
$$


Where $\bar{p}_{H}\left(b_{1}\right)=\left\{p_{2}=p_{1}\right\} \cap\left\{p_{2}=p_{m}\left(c_{H}, 1,1, \phi\right)\right\}$ and

$\tilde{p}_{H}\left(b_{1}\right)=\left\{p_{2}=p_{m}\left(c_{H}, 1,1, \phi\right)\right\} \cap\left\{p_{2}=p\left(c_{H}, 1,0,0\right)\right\}$

Figure 3 shows the second period pricing rule for a type $L$ firm when the firm adopted a MFCC in period one, as given by equation (19) (the pricing rule for a type $H$ firm looks similar). As $p_{2}$ approaches $p\left(c_{L}, 0,0,0\right)$ from above and below, period 2 profits are increasing when $p_{1} \leq$ $p\left(c_{L}, 0,0,0\right)$. For $p_{1}$ greater, but not much greater, than $p\left(c_{L}, 0,0,0\right)$ the type $L$ firm finds it most profitable to set $p_{2}=p_{1}$ and pay no penalty. $p_{1}$ is small enough such that the number of consumers who are covered by the MFCC is relatively large. The firm prefers earning lower profits in period 2 to offering a lower $p_{2}$ and paying a large penalty. As $p_{1}$ gets larger, however, the number of consumers covered by the MFCC becomes smaller. Also, as $p_{1}$ gets larger, $p_{2=} p_{1}$ becomes further from $p\left(c_{L}, 0,0,0\right)$, and so reversion to the full-information price becomes relatively more attractive. When $p_{1} \geq \bar{p}_{L}\left(b_{1}\right)$, the firm prefers offering a lower $p_{2}$ and paying the smaller penalty. If $p_{1}$ is so large that no consumer makes any purchases in period 1, the firm will revert to offering its full-information price in period 2 .

Now that each type of firm's pricing rule for the period 2 subgame has been determined, consider period 1. Consumers are uninformed as to the monopolist's true type at this date. A type $\mathrm{H}$ monopolist may choose to signal its type either through price alone, or by offering a two-part signal of price and a MFCC. In a separating equilibrium, the type $H$ firm chooses $m$ and $p_{1}$ such that a type $L$ firm would prefer to offer $p_{1}=p\left(c_{L}, 0,0,0\right)$. Let the price offered by $H$ in conjunction with a MFCC in a separating equilibrium, $\hat{p}$, satisfy the following incentive compatibility constraint: 


$$
\begin{gathered}
(1+\delta) \Pi\left(p\left(c_{L}, 0,0,0\right), c_{L}, 0,0,0\right) \geq \\
\Pi\left(\hat{p}, c_{L}, 1,0,0\right)+\delta \Pi\left(p\left(c_{L}, 0,1, \phi\right), c_{L}, 0,1, \phi\right) .
\end{gathered}
$$

First consider $\hat{p} \in\left(p\left(c_{L}, 0,0,0\right), \bar{p}_{L}(1)\right]$, in which case $p_{2}=p_{1}=\hat{p}$.

Proposition 1: There exists a Cho-Kreps intuitive equilibrium outcome in which: $p_{1}=p_{2}=\hat{p}$ and $m=1$ for type $H ; p_{1}=p_{2}=p\left(c_{L}, 0,0,0\right)$ for type $L$, where $\hat{p} \in\left(p\left(c_{H}, 1,0,0\right), \bar{p}_{H}(1)\right]$.

The proof to proposition 1 may be found in the Appendix.

To show that signaling with MFCC is less costly, one must first show that $\hat{p} \leq \bar{P}$. From Theorem $1, \bar{P}$ solves

$$
\Pi\left(p\left(c_{L}, 0,0,0\right), c_{L}, 0,0,0\right)=\Pi\left(\bar{P}, c_{L}, 0,0,0\right) .
$$

If $\hat{p} \in\left(p\left(c_{L}, 0,0,0\right), \bar{p}_{L}(1)\right]$, then we can rewrite equation (21) to get:

$$
(1+\delta) \Pi\left(p\left(c_{L}, 0,0,0\right), c_{L}, 0,0,0\right)=\Pi\left(\hat{p}, c_{L}, 1,0,0\right)+\delta \Pi\left(\hat{p}, c_{L}, 0,0,0\right) .
$$

If $\mathrm{d}=0$, then $\hat{p}=\bar{P}$. If $\mathrm{d}<0$, and $\hat{p}=\bar{P}$, then we can rewrite equation (23) to see that:

$$
\begin{gathered}
\underbrace{\Pi\left(\bar{P}, c_{L}, 1,0,0\right)-\Pi\left(p\left(c_{L}, 0,0,0\right), c_{L}, 0,0,0\right)}_{0} \\
\neq \underbrace{\delta\left[\left(p\left(c_{L}, 0,0,0\right), c_{L}, 0,0,0\right)-\Pi\left(\bar{P}, c_{L}, 0,0,0\right)\right]}_{+},
\end{gathered}
$$

because $\Pi\left(\bar{P}, c_{L}, 1,0,0\right)>\Pi\left(\bar{P}, c_{L}, 0,0,0\right)$. As $(\bar{P}-\hat{p})$ increases, both sides of equation (23) increase. By the single-crossing property,

$$
0>\frac{\partial \Pi\left(\bar{P}, c_{L}, 1,0,0\right)}{\partial p}>\frac{\partial \Pi\left(\bar{P}, c_{L}, 0,0,0\right)}{\partial p},
$$


so the right-hand side of (23) increases faster as $(\bar{P}-\hat{p})$ increases than the left-hand side of (23).

Therefore, there must be some $\hat{p} \leq \bar{P}$ such that equation (23) is satisfied.

We must also show that $\hat{p}>p\left(c_{H}, 1,0,0\right)$. First, the following two conditions must be true for a profit-maximizing monopolist:

$$
1>\frac{\partial p\left(c_{H}, 1,0,0\right)}{\partial c}>0
$$

and

$$
\frac{\partial \Pi(p(c, 1,0,0), c, 1,0,0)}{\partial c}<0, \forall c
$$

Equations (26) and (27) imply that $\Pi\left(p, c_{H}, 1,0,0\right)<\Pi\left(p, c_{L}, 1,0,0\right)$, and $p\left(c_{H}, 1,0,0\right)>p\left(c_{L}, 1,0,0\right)$. Equations (26) and (27) also imply that the percentage decrease in profits from a one-percent increase in costs is greater than the percentage decrease in profits from a one-percent increase in price (let ? ${ }^{*}$ represent $\Pi(p(c, 1,0,0), c, 1,0,0)$ and let $p^{*}$ represent $\left.p(c, 1,0,0)\right)$ :

$$
-\frac{\partial \Pi^{*}}{\partial c} \frac{c}{\Pi^{*}}=-\left[\frac{\partial \Pi^{*}}{\partial p} \frac{\partial p^{*}}{\partial c}+\frac{\partial \Pi}{\partial c}\right] \frac{c}{\Pi^{*}}>-\frac{\partial \Pi^{*}}{\partial p} \frac{p^{*}}{\Pi^{*}} .
$$

Now $\hat{p}$ is the price greater than $p\left(c_{L}, 0,0,0\right)$ at which the functions $\Pi\left(p, c_{L}, 1,0,0\right)$ and $\Pi\left(p, c_{L}, 0,0,0\right)$ are equidistant from the value $\Pi\left(p\left(c_{L}, 0,0,0\right), c_{L}, 0,0,0\right)$. By equation (28), as $c_{H}$ gets larger, the value $\Pi\left(p\left(c_{H}, 1,0,0\right), c_{H}, 1,0,0\right)$ ? will decrease "faster" than the value $p\left(c_{H}, 1,0,0\right)$, such that $p\left(c_{H}, 1,0,0\right)=\hat{p}$ only when $c_{H}$ is so large that $\Pi\left(p\left(c_{H}, 1,0,0\right), c_{H}, 1,0,0\right)<\Pi\left(p\left(c_{L}, 0,0,0\right), c_{L}, 0,0,0\right)$. However, for $c_{H}$ that large, no firm would ever consciously choose to be a high-quality firm. Therefore, it must be that $\hat{p}>\left(c_{H}, 1,0,0\right)$. In other 
words, by offering a MFCC the high quality firm can signal its quality with a price between its first-best price and the "next-best" price, $\bar{P}$, from Theorem 1 . In this instance, the MFCC works to lessen the price distortion even though prices are the same in both periods and consumers do not receive refunds on their purchases.

Figure 4 shows the relationships between the profit functions for Type $\mathrm{L}$ and Type $\mathrm{H}$ firms. For a discount rate of $\mathrm{d}=1$, equation (21) holds with equality at $p_{1}=\hat{p}$. As $\delta \rightarrow 0, \hat{p} \rightarrow \bar{P}$ (from below).

Now consider $\hat{p} \in\left(\bar{p}_{L}\left(b_{1}\right), \tilde{p}_{L}\left(b_{1}\right)\right]$, in which case $p_{1}=\hat{p}$ and $p_{2}=p_{m}\left(c_{L}, 0,1, \phi\right)$.

Proposition 2: There exists a Cho-Kreps intuitive equilibrium outcome in which: $p_{1}=\hat{p}$, $p_{2}=p_{m}\left(c_{H}, 1,1, \phi\right)$ for type $H$, and $p_{1}=p_{2}=p\left(c_{L}, 0,0,0\right)$ for type $L$, where $\hat{p} \in\left(\bar{p}_{H}(1), \tilde{p}_{H}(1)\right]$.

The proof to Proposition 2 is in the appendix.

As before, one must first show that $\hat{p} \leq P$ to show that signaling with a MFCC is less costly.

We can rewrite equation (21) to get:

$$
(1+\delta) \Pi\left(p\left(c_{L}, 0,0,0\right), c_{L}, 0,0,0\right) \geq \Pi\left(\hat{p}, c_{L}, 1,0,0\right)+\delta \Pi\left(p\left(c_{L}, 0,1, \phi\right), c_{L}, 0,1, \phi\right) .
$$

which may be further rewritten as:

$$
\begin{gathered}
{\left[\left((1-\delta) \hat{p}+\delta p_{m}\left(c_{L}, 0,1, \phi\right)\right)-c_{L}\right] D(\hat{p}, 1)-\Pi\left(p\left(c_{L}, 0,0,0\right), c_{L}, 0,0,0\right)=} \\
\delta\left[\Pi\left(p\left(c_{L}, 0,0,0\right), c_{L}, 0,0,0\right)-\left(p_{m}\left(c_{L}, 0,1, \phi\right)-c_{L}\right) D\left(p_{m}\left(c_{L}, 0,1, \phi\right), 0\right)\right]
\end{gathered}
$$

As $d \rightarrow 0$, equation (30) becomes identical to equation (9) and $\hat{p}=P$. The remainder of the proof that $\hat{p} \leq P$ is similar to the corresponding part of the proof of proposition 1. By the singlecrossing property, it must be that only a price $\hat{p}=\bar{P}$ could satisfy equation (30). 
It remains to be shown that $\hat{p}>p\left(c_{H}, 1,0,0\right)$. For simplicity, let $\mathrm{d}=1$ and rewrite equation

(30) as:

$$
\begin{gathered}
{\left[\left(p_{m}\left(c_{L}, 0,1, \phi\right)\right)-c_{L}\right] D\left(p_{m}\left(c_{L}, 0,1, \phi\right), 1\right)-\Pi\left(p\left(c_{L}, 0,0,0\right), c_{L}, 0,0,0\right)} \\
-\left[\left(p_{m}\left(c_{L}, 0,1, \phi\right)\right)-c_{L}\right]\left[D\left(p_{m}\left(c_{L}, 0,1, \phi\right), 1\right)-D(\hat{p}, 1)\right]= \\
\Pi\left(p\left(c_{L}, 0,0,0\right), c_{L}, 0,0,0\right)-\left[\left(p_{m}\left(c_{L}, 0,1, \phi\right)\right)-c_{L}\right] D\left(p_{m}\left(c_{L}, 0,1, \phi\right), 0\right)
\end{gathered}
$$

As $\hat{p}$ gets smaller, $p_{m}\left(c_{L}, 0,1, \phi\right) \rightarrow \hat{p}$, until equation (31) converges to equation (23). Then, as in proposition $1, \hat{p}>p\left(c_{H}, 1,0,0\right)$. Relative to the assumptions of Proposition 1, the difference between $\hat{p}$ and H's first-best price may be larger here. Just as under the conditions of Proposition 1, the high quality firm is able to signal its type with less price distortion by offering a MFCC. Unlike in Proposition 1 , consumers, under these different conditions, will receive a partial refund from the high-quality firm. ${ }^{8}$ Under the conditions of either proposition, consumers pay lower prices when the high-quality firm uses both price and a MFCC as a signal of quality than when the firm signals with price alone.

\footnotetext{
${ }^{8}$ The low-quality firm does not pay a penalty because it prefers to offer its full-information price in each period.
} 


\section{A More General Contract}

This paper, so far, has limited the firm to a very specific penalty structure. There are other types of contracts that may also offer the high-quality firm the ability to credibly signal its type to consumers at a lower cost than price signaling alone. Shieh (1996) studies the use of a money-back guarantee (MBG) to help signal product quality. A MBG is a warranty by which consumers receive a partial or full refund of the purchase price should the consumer be dissatisfied with the quality of the good, whether because the good is physically defective or for subjective reasons. ${ }^{9}$ Shieh shows that when consumers are promised a full refund should the good's quality not be as promised (in this case, a defective product is observed), a high-quality producer will be able to signal its type at its first-best price.

There are two definitive differences between my paper and Shieh's. We each begin by assuming different definitions of quality. Shieh defines quality as the probability that a product will break down. I assume that quality differences are more aesthetic. The product works, but there may exist another product with attributes that the consumer desires more. However, this assumption is not crucial to my model. Allowing consumers to exercise a MBG based upon subjective measurements of quality may give rise to moral hazard problems (too many refunds). When a MFCC is exercised it is independent of consumers' perceptions of quality. The MFCC penalty is only paid when the

\footnotetext{
${ }^{9}$ MFCCs are different from MBGs in the type of protection offered the consumer and how that protection is triggered. MBGs protect the consumer from being dissatisfied with the good itself. Retroactive MFCCs protect the consumer from suffering "buyer's remorse" when they find that after purchase, a good has gone on sale at a later date. The consumer of a good with MFCC protection need not be dissatisfied with the good he has purchased -insofar as the good is not defective -- except that he has paid too high a price for it and could have waited to purchase it at a lower price.
} 
low-quality firm lowers its price, which it must in order to make any sales after it has been discovered mimicking a high-quality firm.

The second distinction between my paper and Shieh's may be found in the results. While MFCCs and MBGs are different contracts, they are both capable of allowing producers of high-quality goods to signal their quality with reduced price distortion. Under either type of contract, low-quality producers are unable to afford the associated penalty. ${ }^{10} \mathrm{MBG}$ protection, in the form of a full refund, fully eliminates the price distortion. MFCC protection, a partial refund, partially eliminates price distortion.

What is important for reduced-distortion signaling, however, is not the specific terms of the contract, but that there is an enforceable penalty imposed upon the low-quality producer for mimicking a high-quality firm. The following analysis shows that there is a more general form of contractual penalty with which the high-quality monopolist can signal its type without price distortion. MBGs and MFCCs are variants of this general contract.

All that is necessary for "cost-less signaling" is for the contract to be somehow tied to some measurement (i.e. through either price or observable quality) of the firm's performance and that the penalty be sufficiently large. From equation (10), period two profits are

$$
\Pi\left(p_{2}, c_{i}, b_{2}, m_{1}, \phi\right)=\left(p_{2}-c_{i}\right) D\left(p_{2}, b_{2}\right)-m_{1} \phi
$$

where $\phi>0$ is the penalty paid per-unit of the product sold and $m_{1} \in\{0,1\}$ is the (observable) trigger variable which determines if the penalty goes into effect. The penalty, which is now an endogenous

\footnotetext{
${ }^{10}$ In Shieh's paper, the probability of a product being returned for full refund is too high for a low-quality manufacturer to offer MBG protection. In my model, the penalty associated with lowering prices once quality becomes known is too great for the low-quality firm to offer price protection.
} 
variable, may be triggered by some measurable standard, whether it be price or observable quality (a breakdown).

For the penalty to induce distortion-free signaling, the first-period price will be $p_{1}=p\left(c_{H}, 1,0,0\right)$. The incentive compatibility constraint, equation (21) will become

$$
(1+\delta) \Pi\left(p\left(c_{L}, 0,0,0\right), c_{L}, 0,0,0\right) \geq \Pi\left(p\left(c_{H}, 1,0,0\right), c_{L}, 1,0,0\right)+\delta\left(p_{2}-c_{L}\right) D\left(p_{2}, 0\right)-\delta \phi .
$$

Suppose the penalty were $\phi=p_{1} D\left(p_{1}, b_{1}\right)$, which is equivalent to a money-back guarantee, but is triggered when $p_{2}<p_{1}$, like a MFCC. The type $L$ firm's optimal price in the second period is $p\left(c_{L}, 0,0,0\right)$ (the size of the penalty is independent of $\left.p_{2}\right)$. Therefore, equation (33) may be rewritten as

$$
\Pi\left(p\left(c_{L}, 0,0,0\right), c_{L}, 0,0,0\right)+\delta c_{L} D\left(p\left(c_{H}, 1,0,0\right), 1\right) \geq(1-\delta) \Pi\left(p\left(c_{H}, 1,0,0\right), c_{L}, 1,0,0\right) .
$$

Provided that the discount factor, $\delta$, is large enough, equation (34) will be satisfied. This more general contract, which is a hybrid of an MFCC and MBG, allows distortion-free signaling.

\section{Conclusion}

Best-price guarantees can be an effective signal of a product's quality. A low-quality producer will find that offering a MFCC is unprofitable -- it must be able to lower prices or else face reduced sales in the second period. A high-quality producer finds that it can signal its quality with less price distortion than if it had not offered a best-price contract. Since the contract credibly restricts the firm's actions, consumers know that only a high-quality producer can afford to offer a MFCC. The similarities between Shieh's paper and my own indicate that there exists a more general type of commitment guarantee, one in which the firm 
offers explicitly to pay consumers if the firm misrepresents its type. There is some size of monetary non-performance payment for which a high-quality firm will be able to offer its first-best price.

Contrary to some of the previous literature on best-price guarantees, social welfare should be greater when MFCCs are used as a signal of quality because prices are lower and output is higher than without the contract. In both Cooper (1986) and Butz (1991), MFCCs allow firms to charge higher prices and restrict output. If best-price guarantees are not always harmful to social welfare then these contracts should be dealt with on a case by case basis by antitrust authorities. Further, empirical research into the effects of best-price guarantees upon competition may shed additional light into how judges and the antitrust agencies should properly treat these contracts.

\section{Appendix}

Proposition 1: There exists a Cho-Kreps intuitive equilibrium outcome in which:

$p_{1}=p_{2}=\hat{p}$ and $\mathrm{m}=1$ for type $\mathrm{H} ; p_{1}=p_{2}=p\left(c_{L}, 0,0,0\right)$ for type $\mathrm{L}$, where

$\hat{p} \in\left(p\left(c_{H}, 1,0,0\right), \bar{p}_{H}(1)\right]$

Proof:

In a separating equilibrium, type $L$ does not distort its price, $p_{1}=p_{2}=p\left(c_{L}, 0,0,0\right)$, or its choice of $m$. The price set by the type $H$ firm must solve the incentive compatibility constraint, equation (23):

$$
(1+\delta) \Pi\left(p\left(c_{L}, 0,0,0\right), c_{L}, 0,0,0\right)=\Pi\left(\hat{p}, c_{L}, 1,0,0\right)+\delta \Pi\left(\hat{p}, c_{L}, 0,0,0\right)
$$

The type $L$ firm is indifferent between mimicking its type $H$ counterpart and offering its own full- 
information price and MFCC choice when the type $\mathrm{H}$ firm sets its price according to this constraint.

However, the incentive compatibility constraint may also be met if the type $H$ firm offers a firstperiod price that is lower than its full-information price. However, this lower price is

$\underline{P}$ from equation (9). From Theorem 1, we already know that the type $H$ firm strictly prefers $\bar{P}$ to $\underline{P}$. It remains to be shown that the type $H$ firm will prefer $\hat{p}$ to $\bar{P}$.

The type $H$ firm must do at least as well by charging $p_{1}=p_{2}=\hat{p}$ and offering a MFCC in equilibrium as it would have done by signaling using a higher first period price, $\bar{P}$ and no MFCC:

$$
\Pi\left(\bar{P}, c_{H}, 1,0,0\right)+\delta \Pi\left(p\left(c_{H}, 1,0,0\right), c_{H}, 1,0,0\right) \leq(1+\delta) \Pi\left(\hat{p}, c_{H}, 1,0,0\right)
$$

Equation (A1) may be rewritten as follows:

$$
\begin{gathered}
\left(\hat{p}-c_{H}\right) D(\hat{p}, 1)-\left(\bar{P}-c_{H}\right) D(\bar{P}, 1) \geq \\
\delta\left(p\left(c_{H}, 1,0,0\right)-c_{H}\right) D\left(p\left(c_{H}, 1,0,0\right), 1\right)-\delta\left(\hat{p}-c_{H}\right) D(\hat{p}, 1) .
\end{gathered}
$$

Using equations (9) and (23), we get the following equality:

$$
(1+\delta)\left(\bar{P}-c_{L}\right) D(\bar{P}, 1)=\left(\hat{p}-c_{L}\right) D(\hat{p}, 1)+\delta\left(\hat{p}-c_{L}\right) D(\hat{p}, 0)
$$

Substitute equation (A3) into equation (A2) to get

$$
\begin{gathered}
\left(\hat{p}-c_{H}\right) D(\hat{p}, 1)-\left(\bar{P}-c_{H}\right) D(\bar{P}, 1)+\left(\bar{P}-c_{L}\right) D(\bar{P}, 1)-\left(\hat{p}-c_{L}\right) D(\hat{p}, 1) \geq \\
\delta\left(p\left(c_{H}, 1,0,0\right)-c_{H}\right) D\left(p\left(c_{H}, 1,0,0\right), 1\right)-\delta\left(\hat{p}-c_{H}\right) D(\hat{p}, 1) \\
-\delta\left(\bar{P}-c_{L}\right) D(\bar{P}, 1)+\delta\left(\hat{p}-c_{L}\right) D(\hat{p}, 0)
\end{gathered}
$$

Equation (A4) may be simplified and rewritten as:

$$
\begin{gathered}
\frac{1}{\delta}\left[c_{H}-c_{L}\right][D(\hat{p}, 1)-D(\bar{P}, 1)] \leq \\
{\left[\Pi\left(\hat{p}, c_{H}, 1,0,0\right)-\Pi\left(\hat{p}, c_{L}, 0,0,0\right)\right]-} \\
{\left[\Pi\left(p\left(c_{H}, 1,0,0\right), c_{H}, 1,0,0\right)-\Pi\left(p\left(c_{L}, 0,0,0\right), c_{L}, 0,0,0\right)\right] .}
\end{gathered}
$$

Consider each term in equation (A5). The left-hand side is positive - 
$\frac{1}{\delta}\left[c_{H}-c_{L}\right][D(\hat{p}, 1)-D(\bar{P}, 1)]>0$ as $c_{H}>c_{L}$ and $\hat{p}<\bar{P}$. Both bracketed terms on the right-hand side are also positive. Also, the entire right-hand side is positive. This is easily seen by rewriting the right-hand side of (A5) as follows:

$$
\begin{gathered}
\Pi\left(p\left(c_{L}, 0,0,0\right), c_{L}, 0,0,0\right)-\Pi\left(\hat{p}, c_{L}, 0,0,0\right)> \\
\Pi\left(p\left(c_{H}, 1,0,0\right), c_{H}, 1,0,0\right)-\Pi\left(\hat{p}, c_{H}, 1,0,0\right) .
\end{gathered}
$$

The price $\hat{p}$ is closer to type $H$ 's full-information monopoly price than to type $L$ 's full-information price, so the profit distortion is greater for type $L$ than for type $H$.

Let $\delta^{*}$ be the discount factor such that equation (A5) holds with equality - that is for $\delta=\delta^{*}$, the type $H$ firm is indifferent between charging $p_{1}=p_{2}=\hat{p}$ with an offer of a MFCC and instead charging $p_{1}=\bar{P}, p_{2}=p\left(c_{H}, 1,0,0\right)$ with no MFCC offer. For $\delta>\delta^{*}$, the type $H$ firm strictly prefers to offer a MFCC and charges $p_{1}=p_{2}=\hat{p}$.

There is no type of informed player that could not benefit from an out-of-equilibrium action irrespective of uninformed consumers' beliefs. That is, there exists at least one set of beliefs that consumers might hold for which either the type $L$ firm or the type $H$ firm would find it profitable make an out-of-equilibrium move. The Intuitive Criterion of Cho \& Kreps (1987) specifies then that consumers' beliefs about the identity of the informed player that takes an out-of-equilibrium action must be concentrated upon the type $L$ and type $H$ firms. Let consumers (who are uninformed) believe that any out-of-equilibrium move in period 1 is made by the type $L$ firm with probability one. More formally,

$$
b_{1}=\left\{\begin{array}{cc}
0 & \forall p \in[P, \hat{p}), \\
1 & \text { otherwise } .
\end{array}\right.
$$


The type $L$ firm cannot profitably deviate from its full-information price, $p\left(c_{L}, 0,0,0\right)$, in the first-period given uninformed consumers' beliefs. By equations (9) and (23), the type $L$ firm will strictly prefer $p\left(c_{L}, 0,0,0\right)$ to any $p>\hat{p}$ or any $p<\underline{P}$ even though consumers' beliefs are most favorable at these prices. Similarly, when consumers' beliefs are least favorable, the type $L$ firm will strictly prefer $p\left(c_{L}, 0,0,0\right)$ to any other $p \in[P, \hat{p})$.

The type $\mathrm{H}$ firm cannot profitably deviate from offering the price $p_{1}=\hat{p}$ given uninformed consumers' beliefs if $\delta \geq \delta^{*}$. By equation (A5), $\hat{p}$ is more profitable than $\bar{P}$ and therefore, also any price $p>\bar{P}$. The type $\mathrm{H}$ firm will also strictly prefer $\hat{p}$ to any $p \in[P, \hat{p})$, where consumers' beliefs are unfavorable. Therefore, given consumers' beliefs concerning an out-of-equilibrium action, neither type of firm will deviate from the equilibrium and the equilibrium satisfies the Intuitive Criterion of Cho \& Kreps. QED

Proposition 2: There exists a Cho-Kreps intuitive equilibrium outcome in which: $p_{1}=\hat{p}, p_{2}=p_{m}\left(c_{H}, 1,1, \phi\right)$ for type $H$, and $p_{1}=p_{2}=p\left(c_{L}, 0,0,0\right)$ for type $L$, where $\hat{p} \in\left(\bar{p}_{H}(1), \tilde{p}_{H}(1)\right]$.

Proof:

In a separating equilibrium, type $L$ does not distort its price, $p_{1}=p_{2}=p\left(c_{L}, 0,0,0\right)$, or its choice of $m$. The price set by the type $H$ firm must solve the incentive compatibility constraint, equation (29):

$$
(1+\delta) \Pi\left(p\left(c_{L}, 0,0,0\right), c_{L}, 0,0,0\right) \geq \Pi\left(\hat{p}, c_{L}, 1,0,0\right)+\delta \Pi\left(p\left(c_{L}, 0,1, \phi\right), c_{L}, 0,1, \phi\right) .
$$


The type $L$ firm is indifferent between mimicking its type $H$ counterpart and offering its own fullinformation price and MFCC choice when the type $H$ firm sets its price according to this constraint.

However, the incentive compatibility constraint may also be met if the type $H$ firm offers a firstperiod price that is lower than its full-information price. However, this lower price is $\underline{P}$ from equation (9). From Theorem 1, we already know that the type $H$ firm strictly prefers $\bar{P}$ to $\underline{P}$. It remains to be shown that the type $H$ firm will prefer $\hat{p}$ to $\bar{P}$..

The type $H$ firm must do at least as well by charging $p_{1}=\hat{p}, p_{2}=p_{m}\left(c_{H}, 1,1, \phi\right)$ and offering a MFCC in equilibrium as it would have done by signaling using a higher first period price, $\bar{P}$ and no MFCC:

$\Pi\left(\bar{P}, c_{H}, 1,0,0\right)+\delta \Pi\left(p\left(c_{H}, 1,0,0\right), c_{H}, 1,0,0\right) \leq \Pi\left(\hat{p}, c_{H}, 1,0,0\right)+\delta \Pi\left(p_{m}\left(c_{H}, 1,1, \phi\right), c_{H}, 1,1, \phi\right)$

Equation (A8) may be rewritten as follows:

$$
\begin{gathered}
\left(\hat{p}-c_{H}\right) D(\hat{p}, 1)-\left(\bar{P}-c_{H}\right) D(\bar{P}, 1) \geq \\
\delta\left(p\left(c_{H}, 1,0,0\right)-c_{H}\right) D\left(p\left(c_{H}, 1,0,0\right), 1\right)-\delta\left(p_{m}\left(c_{H}, 1,1, \phi\right)-c_{H}\right) D\left(p_{m}\left(c_{H}, 1,1, \phi\right), 1\right) \\
+\delta\left(\hat{p}-p_{m}\left(c_{H}, 1,1, \phi\right)\right) D(\hat{p}, 1) .
\end{gathered}
$$

Using equations (9) and (29), we get the following equality:

$$
\begin{gathered}
(1+\delta)\left(\bar{P}-c_{L}\right) D(\bar{P}, 1)=\left(\hat{p}-c_{L}\right) D(\hat{p}, 1) \\
+\delta\left(p_{m}\left(c_{L}, 0,1, \phi\right)-c_{L}\right) D\left(p_{m}\left(c_{L}, 0,1, \phi\right), 0\right) \\
-\left(\hat{p}-p_{m}\left(c_{L}, 0,1, \phi\right)\right) D(\hat{p}, 1)
\end{gathered}
$$

Substitute equation (A10) into equation (A9) to get

$$
\begin{gathered}
\left(\hat{p}-c_{H}\right) D(\hat{p}, 1)-\left(\bar{P}-c_{H}\right) D(\bar{P}, 1)+\left(\bar{P}-c_{L}\right) D(\bar{P}, 1)-\left(\hat{p}-c_{f}\right) D(\hat{p}, 1) \geq \\
\delta\left(p\left(c_{H}, 1,0,0\right)-c_{H}\right) D\left(p\left(c_{H}, 1,0,0\right), 1\right)-\delta\left(p_{m}\left(c_{H}, 1,1, \phi\right)-c_{H}\right) D\left(p_{m}\left(c_{H}, 1,1, \phi\right), 1\right) \\
+\delta\left(\hat{p}-p_{m}\left(c_{H}, 1,1, \phi\right)\right) D(\hat{p}, 1)-\delta\left(\bar{P}-c_{L}\right) D(\bar{P}, 1) \\
+\delta p_{m}\left(c_{H}, 1,1, \phi\right) D\left(p_{m}\left(c_{H}, 1,1, f\right), 0\right)-\delta\left(\hat{p}-p_{m}\left(c_{H}, 1,1, \phi\right)\right) D(\hat{p}, 1)
\end{gathered}
$$


Recalling that

$$
\begin{gathered}
\Pi\left(p_{m}\left(c_{H}, 1,1, \phi\right), c_{H}, 1,1, \phi\right)= \\
\left(p_{m}\left(c_{H}, 1,1, \phi\right)-c_{H}\right) D\left(p_{m}\left(c_{H}, 1,1, \phi\right), 1\right)-\left(\hat{p}-p_{m}\left(c_{H}, 1,1, \phi\right)\right) D(\hat{p}, 1),
\end{gathered}
$$

and

$$
\begin{gathered}
\Pi\left(p_{m}\left(c_{L}, 0,1, \phi\right), c_{L}, 0,1, \phi\right)= \\
\left(p_{m}\left(c_{L}, 0,1, \phi\right)-c_{L}\right) D\left(p_{m}\left(c_{L}, 0,1, \phi\right), 0\right)-\left(\hat{p}-p_{m}\left(c_{L}, 0,1, \phi\right)\right) D(\hat{p}, 1),
\end{gathered}
$$

equation (A11) may be simplified and rewritten as:

$$
\begin{gathered}
\left(c_{H}-c_{L}\right)[D(\hat{p}, 1)-D(\bar{P}, 1)] \leq \\
\delta\left[\Pi\left(p_{m}\left(c_{H}, 1,1, \phi\right), c_{H}, 1,1, \phi\right)-\Pi\left(p_{m}\left(c_{L}, 0,1, \phi\right), c_{L}, 0,1, \phi\right)\right]- \\
\delta\left[\Pi\left(p\left(c_{H}, 1,0,0\right), c_{H}, 1,0,0\right)-\Pi\left(p\left(c_{L}, 0,0,0\right), c_{L}, 0,0,0\right)\right] .
\end{gathered}
$$

Consider each term in equation (A14). The left-hand side is positive-

$\left(c_{H}-c_{L}\right)[D(\hat{p}, 1)-D(\bar{P}, 1)]>0$-as $c_{H}>c_{L}$ and $\hat{p}<\bar{P}$. Both bracketed terms on the right-hand side are also positive. Also, the entire right-hand side is positive. This is easily seen by rewriting the right-hand side of (A14) as follows:

$$
\begin{gathered}
\Pi\left(p\left(c_{L}, 0,0,0\right), c_{L}, 0,0,0\right)-\Pi\left(p_{m}\left(c_{L}, 0,1, \phi\right), c_{L}, 0,1, \phi\right)> \\
\Pi\left(p\left(c_{H}, 1,0,0\right), c_{H}, 1,0,0\right)-\Pi\left(p_{m}\left(c_{H}, 1,1, \phi\right), c_{H}, 1,1, \phi\right) .
\end{gathered}
$$

The price $p_{m}\left(c_{H}, 1,1, \phi\right)$ is closer to type H's full-information monopoly price than $p_{m}\left(c_{L}, 0,1, \phi\right)$ is to type $L$ 's full-information price. Also, the penalty paid by the type $L$ firm is greater than the penalty paid by the type $H$ firm - the type $H$ firm need not lower price as much in period two as the type $L$ firm must. Therefore, the profit distortion is greater for type $L$ than for type $H$.

Let $\delta^{* *}$ be the discount factor such that equation (A14) holds with equality - that is for $\delta=\delta^{* *}$, the type $H$ firm is indifferent between charging $p_{1}=\hat{p}, p_{2}=p_{m}\left(c_{H}, 1,1, \phi\right)$ with an offer of a MFCC 
and instead charging $p_{1}=\bar{P}, p_{2}=p\left(c_{H}, 1,0,0\right)$ with no MFCC offer. For $\delta>\delta^{* *}$, the type $H$ firm strictly prefers to offer a MFCC and charge $p_{1}=\hat{p}, p_{2}=p_{m}\left(c_{H}, 1,1, \phi\right)$.

There is no type of informed player that could not benefit from an out-of-equilibrium action irrespective of uninformed consumers' beliefs. That is, there exists at least one set of beliefs that consumers might hold for which either the type $L$ firm or the type $H$ firm would find it profitable make an out-of-equilibrium move. The Intuitive Criterion of Cho \& Kreps (1987) specifies then that consumers' beliefs about the identity of the informed player that takes an out-of-equilibrium action must be concentrated upon the type $L$ and type $H$ firms. Let consumers (who are uninformed) believe that any out-of-equilibrium move in period 1 is made by the type $L$ firm with probability one. More formally,

$$
b_{1}=\left\{\begin{array}{cc}
0 & \forall p \in[P, \hat{p}), \\
1 & \text { otherwise } .
\end{array}\right.
$$

The type $L$ firm cannot profitably deviate from its full-information price, $p\left(c_{L}, 0,0,0\right)$, in the first-period given uninformed consumers' beliefs. By equations (9) and (29), the type $L$ firm will strictly prefer $p\left(c_{L}, 0,0,0\right)$ to any $p>\hat{p}$ or any $p<\underline{P}$ even though consumers' beliefs are most favorable at these prices. Similarly, when consumers' beliefs are least favorable, the type $L$ firm will strictly prefer $p\left(c_{L}, 0,0,0\right)$ to any other $p \in[P, \hat{p})$.

The type $H$ firm cannot profitably deviate from offering the price $p_{1}=\hat{p}$ given uninformed consumers' beliefs if $\delta \geq \delta^{* * *}$. By equation (A14), $\hat{p}$ is more profitable than $\bar{P}$ and therefore, also any price $\hat{p}>\bar{P}$. The type $H$ firm will also strictly prefer $\hat{p}$ to any $p \in[\underline{P}, \hat{p})$, where consumers' beliefs are unfavorable. Therefore, given consumers' beliefs concerning an out-of-equilibrium action, neither type of firm will deviate from the equilibrium and the 
equilibrium satisfies the Intuitive Criterion of Cho \& Kreps. $Q E D$

\section{References}

Bagwell, K. and Riordan, M. "High and Declining Prices Signal Product Quality." American Economic Review, Vol. 81 (1991), pp. 224-239.

Bagwell, K. "Optimal Export Policy for a New-Product Monopoly." American Economic Review, Vol. 81 (1991), pp. 1156-1169.

Besanko, D. and Lyon, T.P. "Equilibrium Incentives for Most-Favored Customer Clauses in an Oligopolistic Industry." International Journal of Industrial Organization, Vol. 11 (1993), pp. 347-367.

Butz, D.A. "Durable-Good Monopoly and Best-Price Provisions." American Economic Review, Vol. 80 (1990), pp. 1062-1076.

Cho, I. and Kreps, D.M. "Signaling Games and Stable Equilibria." Quarterly Journal of Economics, Vol. 102 (1987), pp. 179-221.

Cooper, T.E. "Most-favored-customer Pricing and Tacit Collusion." Rand Journal of Economics, Vol. 17 (1986), pp. 377-388.

Coase, R. "Durability and Monopoly." Journal of Law and Economics, Vol. 15 (1972), pp. 143149.

Crocker, K.J. and Lyon, T.P. "What do 'Facilitating Practices' Facilitate? An Empirical Investigation of Most-Favored-Nation Clauses in Natural Gas Contracts." Journal of Law and Economics, Vol. 37 (1994), pp. 297-322.

Klein, B. and Leffler, K.B. "The Role of Market Forces in Assuring Contractual Performance." Journal of Political Economy, Vol. 89 (1981), pp. 615-641.

Kreps, D.M. and Wilson, R. "Sequential Equilibria." Econometrica, Vol. 50 (1982), pp. 863-894.

Neilson, W.S. and Winter, H. "Bilateral Most-Favored-Customer Pricing and Collusion." Rand Journal of Economics, Vol. 24 (1993), pp. 147-155.

Riordan, M.H. "Monopolistic Competition with Experience Goods." Quarterly Journal of Economics, Vol. 101 (1986), pp. 265-279.

Shapiro, C. "Premiums for High Quality Products as Returns to Reputations." Quarterly Journal of 
Economics, Vol. 98 (1983), pp. 659-680.

Shieh, S. "Price and Money-Back Guarantees as Signals of Product Quality." Journal of Economics and Management Strategy, Vol. 5 (1996), pp. 361-378. 


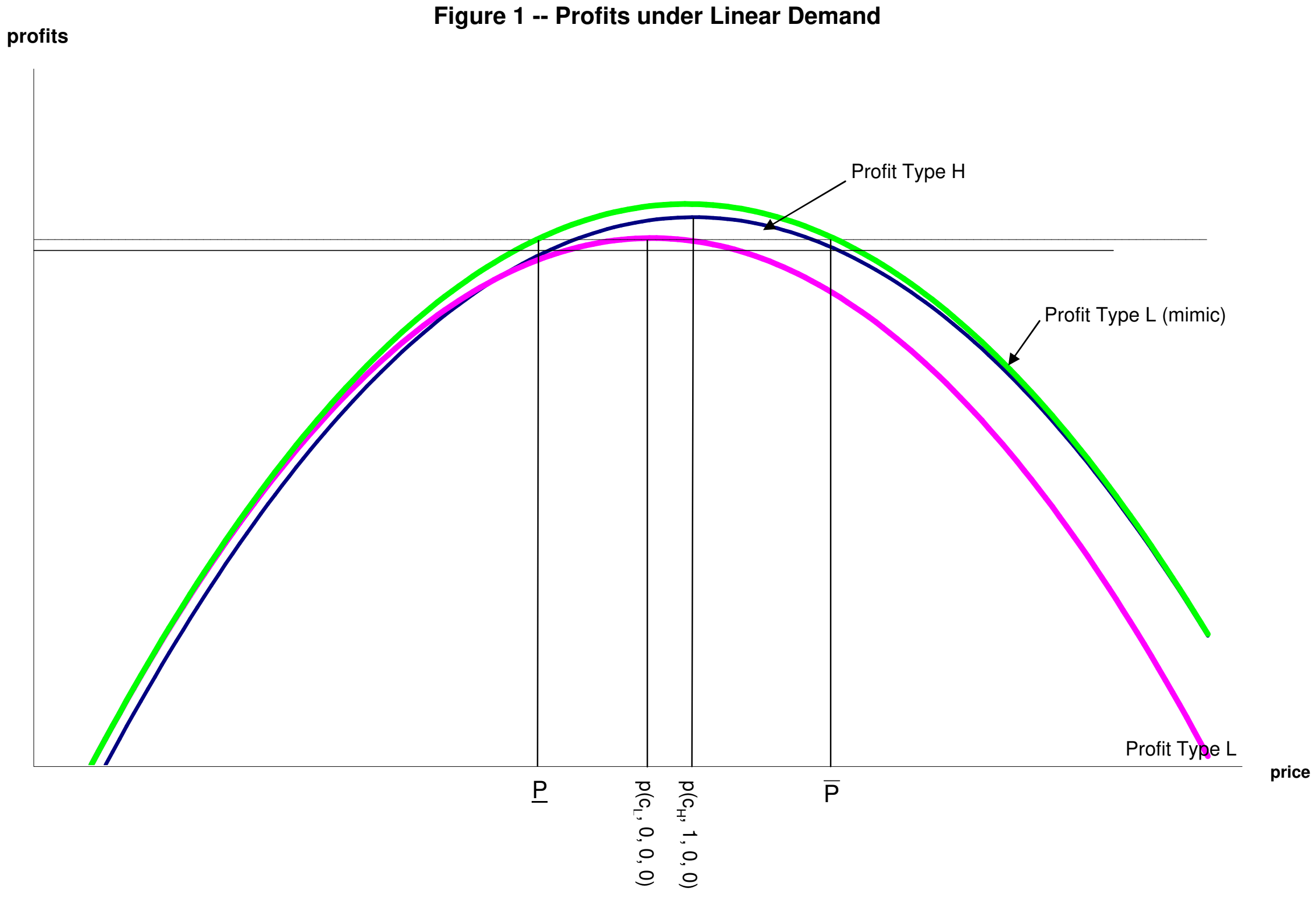




\section{Figure 2 -- Profits under Constant Elasticity Demand Curve}

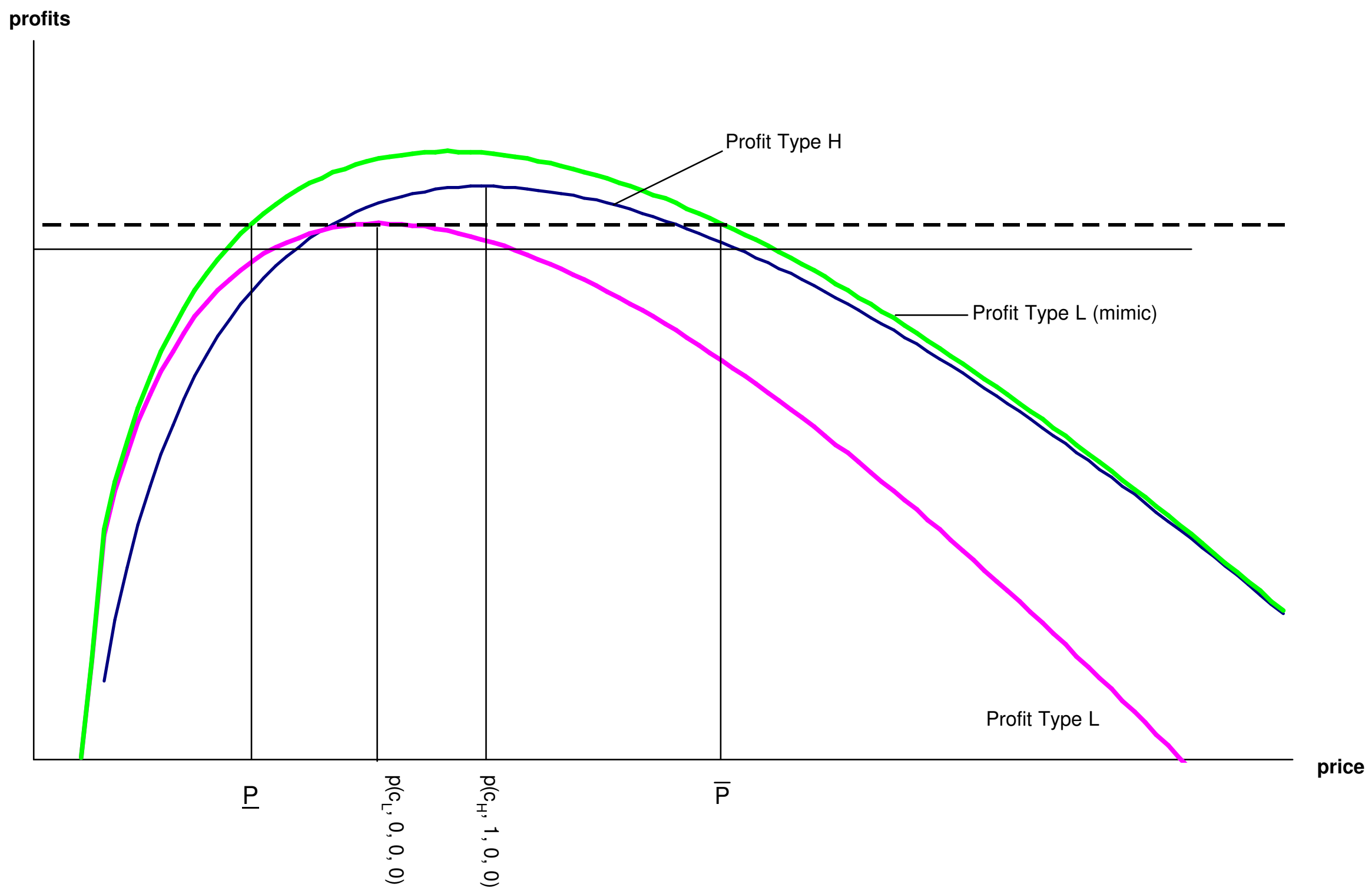


$\mathrm{p}_{2}$

Figure 3-- Period 2 price as a function of period one price for type $L$ firm

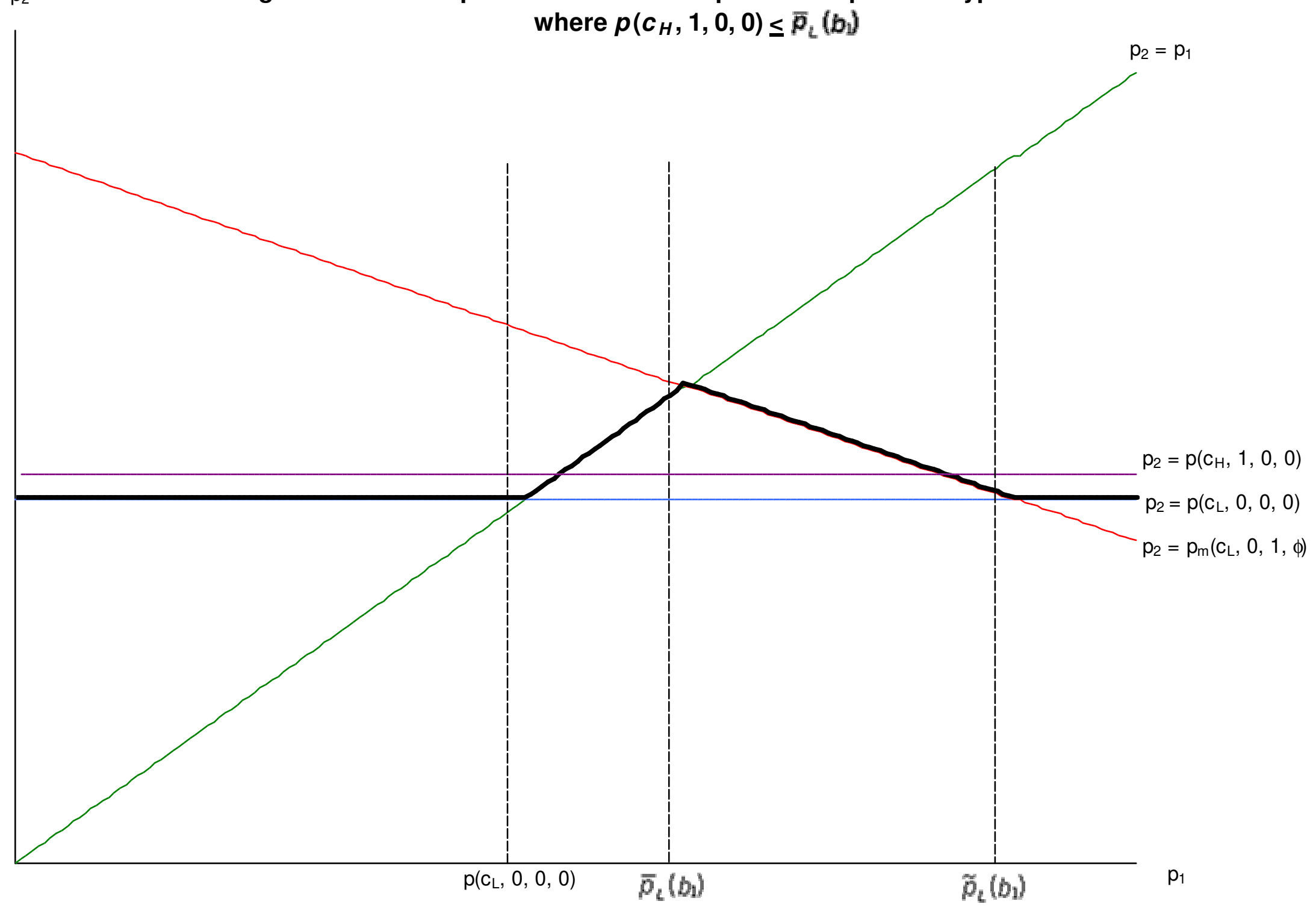


Figure 4 -- Profit functions under linear demand

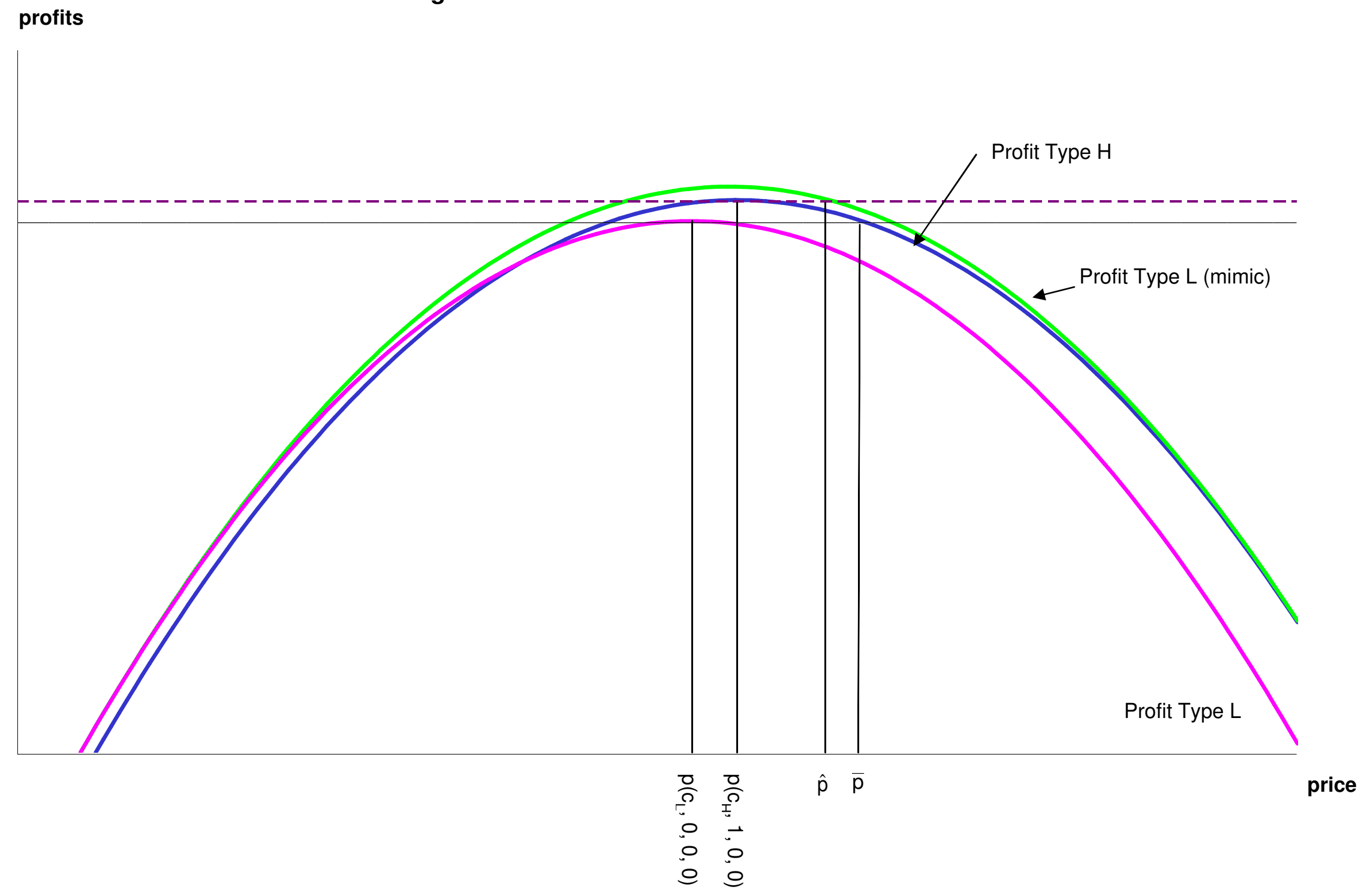

